\title{
A Network Optimization Research for Product Returns Using Modified Plant Growth Simulation Algorithm
}

\author{
Xuping Wang, ${ }^{1,2}$ Jian Qiu, ${ }^{1}$ Tong Li, ${ }^{2}$ and Junhu Ruan ${ }^{3}$ \\ ${ }^{1}$ Institute of Systems Engineering, Dalian University of Technology, Dalian 116024, China \\ ${ }^{2}$ School of Business, Dalian University of Technology, Panjin 124221, China \\ ${ }^{3}$ College of Economics and Management, Northwest A\&F University, Yangling 712100, China \\ Correspondence should be addressed to Xuping Wang; wxp@dlut.edu.cn
}

Received 15 September 2016; Revised 4 November 2016; Accepted 25 December 2016; Published 9 February 2017

Academic Editor: Lu Zhen

Copyright (C) 2017 Xuping Wang et al. This is an open access article distributed under the Creative Commons Attribution License, which permits unrestricted use, distribution, and reproduction in any medium, provided the original work is properly cited.

\begin{abstract}
As product returns are eroding Internet retail profit, managers are continuously striving for a more scientific and efficient network layout to arrange the returned goods. Based on a three-echelon product returns network, this paper proposes a mixed integer nonlinear programming model with the aim of minimizing total cost and creates a high-efficiency method, the Modified Plant Growth Simulation Algorithm (MPGSA), to optimize the problem. The algorithm handles the objective function and the constraints, respectively, requiring no extrinsic parameters and provides a guiding search direction generated from the assessment of the current solving state. Above all, MPGSA keeps a great balance between concentrating growth opportunities on the outstanding growth points and expanding the searching scope. The improvements give the revaluating and reselecting chances to all growth points in each iteration, enhancing the optimization efficiency. A case study illustrates the effectiveness and robustness of MPGSA compared to its original version, Plant Growth Simulation Algorithm, and other approaches, namely, Genetic Algorithm, Artificial Immune System, and Simulated Annealing.
\end{abstract}

\section{Introduction}

Product returns have been one of the main sources resulting in inefficiency in Internet retail market, eroding retailers' profits. According to a survey [1], the products returned have occupied 22 percent averagely of the total online retailing amount. Most retailers have viewed this series of costs resulting from product returns as unavoidable items. However, few of them get a clear understanding of the composition of product return losses and cannot master an effective method to avoid the losses.

The design of a reverse logistics network for product returns has become an important research content since it grasps the attention of the logistics industry increasingly. Designing a proper returns network can reduce the total cost of the network to provide more space for augmenting the retailing profits and provide customers with satisfactory experiences through the after-sale links and help producers arrange the following works concerning recovering, refreshing, and reproducing. The content of reverse logistics typically includes transporting, storing, recovering, recycling, remanufacturing, redistributing, and discarding. Product returning is a necessary step in the process. Rabinovich et al. [2] and Wood [3] separately found that product type and product return policy would probably influence customers' decisions on returning in the Internet retail market. Furthermore, retailers can take actions to reduce product returns, such as selling the products that customers can easily retrieve online and evaluate and setting more rigorous return policies $[4,5]$. Although it is true that these measures can reduce the amount of returns, the scope of applying them in the actual marketing operation is very narrow, running in the opposite direction of diversification trend of online retail commodity. On the other hand, retailers reluctant to make a strict return policy alienate themselves from the customers. Therefore, retailers should do some self-reflection, looking 
for a way to improve their service capability and market competitiveness. Undoubtedly, it is one of the important tasks to build a scientific and reasonable reverse logistics network.

This paper proposes a mixed integer nonlinear programming model, which corresponds to a three-echelon product returns network, to find out the number and location of initial collection points (ICPs) and centralized return centers (CRCs) required in efficient collection and return systems and the maximum holding time of each ICP for clustering small volumes of returned products into a large shipment. Moreover, this research for the first time introduces the Plant Growth Simulation Algorithm (PGSA) to address the aforementioned problem and transforms it into the Modified Plant Growth Simulation Algorithm (MPGSA) with three improvements. Under the same condition of experiment data, having compared the results using Genetic Algorithm (GA), Artificial Immune System (AIS), and Simulated Annealing (SA), the comparison result shows that the average total cost of the product returns network is reduced significantly using MPGSA, and the solutions have good stability.

This paper is organized as follows. In Section 2, relevant studies are reviewed. Section 3 proposes a mathematical model minimizing the total cost of the product return network. Section 4 introduces the MPGSA to solve the problem. In Section 5, we carry out an experiment and analyze the theoretical results and then examine the stability of MPGSA. We carry out a sensitivity analysis to identify the factors influencing the total cost in Section 6 and conclude the work in Section 7.

\section{Literature Review}

Researches on reverse logistics network design can be categorized into two types [6, 7]: Closed-Loop Reverse Logistics Network Design (CLRLND) and Open-Loop Reverse Logistics Network Design (OLRLND). OLRLND can be called reverse logistics network design in a narrow sense, which encompasses the reverse logistics tasks like reverse distribution planning and returns management. Combination of forward and reverse logistics networks, which concentrates on the design of reverse logistics network, will structure a closed-loop reverse logistics network [7]. Relevant studies of these two types are summarized separately in this section.

2.1. Closed-Loop Reverse Logistics Network Design. Consideration of researches on CLRLND is comprehensive, covering all the fields such as the return of goods, product maintenance, product refurbishment, component reuse, refabrication, and discard [6]. Important topics in this area are collection and distribution of products and the coordination between producing plan and reverse logistics. Guide Jr. and van Wassenhove [8] tracked the development of closed-loop supply chain and found that the rise of remanufacturing is the first stage of it. The concept of remanufacturing in the early days was put forward for prolonging the service life of the high-value and low-volume items, such as locomotive engines and aircraft. At that time, the hardest initially was the scale of the problem. Products were composed of tens of thousands of components and parts, which brought about incredible challenges for the arrangement of disassembly, remanufacturing, and reassembly. In Europe, the Waste Electrical and Electronic Equipment Directive (WEEE Directive) became European Law in 2003, setting collection, recycle, and recovery targets for various electrical goods [9]. Environmental and social pressures are forcing managers to improve the holistic operation of their logistics networks.

For CLRLND, different researchers have various thoughts for specific problems. Consumer durables generally adopted modular structured design; in other words, they were composed of many modules which are characterized by distinct life cycles. Then, the modules required different recycling and recovering processes. For the modular products such as personal computers, Kaya et al. [10] found that correctly estimating the amount of returns is much more important than correctly estimating the market demand, and they made a suggestion: in the first phase, the manager should decide the optimal number of disassembly and refurbishing sites to open while considering the actual situation of market demand and returns level; in the second phase, the manager should give the operational decision for fixed capacities, like production and inventory rates. Jeihoonian et al. [11] introduced the disassembly tree in the process of assessing the quality status of return streams of durable products. The analysis tool showed decision-makers with a plain tree diagram to evaluate the qualities of modules, parts, and residues, even raw materials. Min et al. [12] studied the spatial and temporal consolidation of returns in a closedloop supply chain network, which has been widely applied in the forward supply chain design, with the aim of providing a minimum-cost solution for the network design. With the consideration of the probable gain achieved from selling the maintained products, Eskandarpour et al. [13] believed that this part of profit should be incorporated into the overall plan. The work represented a classical direction in CLRLND research changing people's conception.

With the problems being gradually prominent, like environmental degradation and resource scarcity, more and more researchers have taken the environmental factors into account while designing a closed-loop supply chain. Fleischmann et al. [14] proposed a model with the aim of finding a balance between reducing the cost of the recycling network and decreasing the environmental impact. More recently, to find a tradeoff between economic benefit and environmental influence, Chaabane et al. [15] introduced the life-cycle assessment principles in the model and assessed the environmental impact with carbon dioxide emission; the conclusion suggested that the environmental strategy would be meaningful if current legislation and Emission Trading Schemes are strengthened and harmonized at the global level. Guide Jr. et al. [16] made an investigation and then realized that most studies had been seeking the lowest operation cost and set a loose demand on the processing period of returns, which made the reuse ratio of returns very limited. Due to the return delay, the loss of the short-life-cycle and time-sensitive goods was more than $30 \%$, which was contrary to the original intention of pursuing cost optimization. For that, Guide Jr. et 
al. [16] designed a model to minimize the operation cost of the returns network and maintain the recoverable product value and recommended the time-sensitive industry to react in a timely manner and the time-insensitive industry to pursue profit. Combination of the reverse logistics and the closedloop supply chain gradually converted the research objective from pursuing the lowest cost to achieving a profitable management [8].

Besides the economic and environmental perspectives, Ramos et al. [17] inventively took the social factor into consideration, the drivers' working hours. The transport work consumed the drivers fast bringing about various kinds of physical damage. Too much pressure would cause the driver to fret and even give rise to traffic accidents. Therefore, more and more scholars have concerned the social perspective in supply chain design. Goel et al. [18] referred to the Australian law and scheduled arrangement for heavy truck drivers coupled with time window constraints. Devika et al. [19] considered the employment opportunity that could be created and the employee security that could be ensured along the supply chain. Other aspects of the social perspective also included the quantifiable benefits (such as salary, pension, and holiday) and the nonquantifiable factors (such as workplace design, accident prevention measures, ergonomic work stress, development and career opportunity, and the flexibility of working time), both of which would affect the employee's job satisfaction. These works represent a research hotspot in the coming decades, Sustainable Operations, which aims equally at sustainability in the economic, environmental, and social senses [6]. But it is still blurred how to quantify the social objective scientifically and how to apply theory into practice.

Having retrospected the development trajectory of CLRLND, there has been an extension of scholars' perspective, from the single cost optimization to the further pursuit of an environment-friendly and harmonious society, making the mathematical model closer to the real world, but at the same time bringing about some unavoidable maladies. CLRLND covers too many interlinked fields. What happens to one part happens to the whole body. In order to meet the need of getting a feasible solution and to pursue the entire optimization effect, these researches chose to ignore the local details in the modeling and calculating stages. Rough network design in the end left only target files or requirement documents to the decision-makers, which is hard to promote the industrial transformation and upgrading.

2.2. Open-Loop Reverse Logistics Network Design. Open-loop reverse logistics network is a part of the closed-loop reverse logistics network, mainly focusing on the issue of returning products. Although the links in OLRLND are fewer, the depiction of each one is much more detailed and complete. For example, in the CLRLND study of Chaabane et al. [15], the objective function of the proposed model contained as many as 9 parts, but the depiction of each part was simple and rough. Therefore, it is thoroughly meaningful to focus the work on improving the process of returning products.
In the field of OLRLND related to product returns, Min et al. [20] proposed a mixed integer nonlinear programming model based on a three-echelon product returns network to solve the location-allocation problem. On that basis, Diabat et al. [21] used the algorithms, GA and AIS, to optimize the problem and got a better result from AIS. Recently, both Zaarour et al. [22] and Ghezavati and Nia [23] made light modifications on the model of Min et al. [20]. The former transformed it to a linear form; the latter added a new dimension concerning product type to the model. In these studies, the portrayals of product returns network were detailed focusing on just collecting returns in a costeffective network. And the managerial suggestions generated in the models were crystal clear and easy-controlled for company managers. To the returns management of the time-sensitive perishable commodity, goods accumulation and bulk transport would reduce the shipping cost, but simultaneously the delay would result in the decrease of market value. For this reason, Ruiz-Benítez et al. [24] looked for the optimal collection period of perishable products and explored the value of information sharing between the collection points and the central processing facilities. Ruan and Shi [25] provided an Internet of Things-based framework for monitoring fruit e-commerce deliveries and an approach for assessing the freshness of in-transit fruits. The returns management can get useful information promptly and help arrange the transportation tasks to reduce the loss of goods market value. In the online retail market, disclosure of inventory levels would give the customers a sense of commodity shortages, thereby promoting sales [26]; Rao et al. [1] tracked these orders sold due to the sense of shortages and found that they have a higher likelihood of being returned. As mentioned before, problems' depiction in CLRLND is too rough to provide the easy-controlled solution. In order to solve the problem correctly and efficiently, the optimization models and algorithms adopted are very important. In combination with the emerging new characteristics of the environment, a lot of researches have been continuously providing new ideas and methods to the traditional problems, improving the efficiency of relevant management work. With the rapid development in computational technologies, new high-performance algorithms are needed to improve the performance in services and operations management.

This paper introduces a high-efficiency method, the Plant Growth Simulation Algorithm, to optimize the product returns network. PGSA handles the objective function and the constraints separately requiring no additional control parameters and provides a guiding search direction that continuously changes with the change of the objective function value, which makes it suitable for solving the problem. In the meantime, this research makes a series of improvements on PGSA according to the specific problem, transforming it to MPGSA mainly through expanding the search range. The results show that the MPGSA optimization effect is obviously enhanced compared to other algorithms and its original version and has good stability. These improvements on PGSA can also be applied optimizing other similar problems. 


\section{Problem Definition}

As the commercial and competitive pressure in business increases, there is always a problem faced by companies of providing a highly efficient and convenient service for product returns, to enhance the corporate image and maintain a good relationship with the customers. For example, enterprises like Dell and HP not only accept returns from retailers, but also provide compensation to the retailers when the amount of returns is well controlled [27]. This makes the acceptance of returns a costly service. Lots of producers and logistics providers are looking for a reasonable overall arrangement for product returns. A network of managing returns generally consists of initial collection points (ICPs) and centralized return centers (CRCs). A client launches a return-merchandise application and sends back the goods to an ICP; the ICP aggregates the client returns into a large shipment and transports it to a CRC.

As a network covers a vast area, it is hard to carry out the direct return from customers to CRCs, due to the high cost of establishing CRCs and the natural willingness of customers to pick a nearby site to return the goods. So, it is necessary to set up small-scale and dense-coverage ICPs. Companies would rather rent ICPs paying the rent expense periodically than build them with a lot of investment. And they can easily adjust their network layout to adapt to the changing needs. Considering that the capacity of an ICP is small and clients return a wide variety of small-volume products, each ICP requires days to aggregate returns. Moreover, the centers of the product returns network play an imperative role in reverse logistics $[10,15,28,29]$. They connect ICPs to a manufacturing center (or a repair center, a recycle center) and provide rapid response for some damage-free or defect-free products. The large-scale and small-amount CRCs require large investment on construction cost in the initial stage. Once established, they will be a part of a company's assets and will be operated for a long term.

In short, this study is going to determine where to locate the ICPs to minimize the distance from customers to the collection points; where to locate the CRCs to minimize the shipping distance from ICPs to manufacturing centers; how many ICPs and CRCs are required to provide convenience for clients and, at the same time, minimize the cost of preparing facilities and handling returns; how long the period is to aggregate returns at each ICP for saving shipment cost; how to arrange the product flows from ICPs to CRCs while considering the capacities of return centers. There are no forward logistics or horizontal transport in the network. In order to find a unified way to address the above issues which involve some conflicting elements, this study forms a mixed integer nonlinear programming model considering the model in Diabat et al.s paper [21], with the aim of minimizing the total cost of the returns network. The model is based on the following assumptions [20].

(1) For the purpose of executing unified management, product returns from a customer cannot bypass the ICP to be delivered directly to the CRCs. And it is necessary to use the ICP to aggregate the small-volume returns in a way to reduce the shipment cost.
(2) Considering the small volume of customers' returns, each ICP in a consolidation period has sufficient capacity to hold the returns from the area under its administration.

(3) Each customer who has a need to return products is assigned to his/her nearest ICP. Then, the transportation cost coming from shipping returns from a customer to his/her nearest ICP is negligible given the short distance between them.

(4) The location-allocation plan covers a planning horizon, within which no substantial changes are incurred in customer demands and the transportation infrastructure.

\subsection{Indices}

$i$ : index for customers; $i \in I$

$j$ : index for initial collection points; $j \in J$

$k$ : index for centralized return centers; $k \in K$

\subsection{Model Parameters}

$a_{j}$ : annual cost of renting initial collection point $j$

$b$ : daily inventory carrying cost per unit at initial collection points

$w$ : working days per year

$r_{i}$ : daily volume of products returned by customer $i$

$h$ : daily product handling cost per unit at initial collection points

$q_{k}$ : establishing cost of centralized return center $k$

$m_{k}$ : inventory capacity of centralized return center $k$

$d_{i j}$ : distance between customer $i$ and initial collection point $j$

$d_{j k}$ : distance between initial collection point $j$ and centralized return center $k$

$l$ : allowable maximum distance between customers and initial collection points

$E$ : unit freight rate

$\alpha$ : discount rate (depends on shipping volume)

$\beta$ : penalty rate (depends on shipping distance)

$p_{1}, p_{2}$ : indicators for discount rate

$q_{1}, q_{2}$ : indicators for penalty rate

$z$ : minimum number of established initial collection points

$g$ : minimum number of established centralized return centers

$M$ : arbitrarily large number

\subsection{Decision Variables}

$X_{j k}$ : product volume returned from initial collection point $j$ to centralized return center $k$

$T_{j}$ : maximum holding time (in days) at initial collection point $j$ 
$Y_{i j}: 1$ if customer $i$ is allocated to initial collection point $j, 0$ otherwise

$Z_{j}: 1$ if an initial collection point is established at site $j, 0$ otherwise

$G_{k}: 1$ if a centralized return center is established at site $k, 0$ otherwise

3.4. Mathematical Model. A mixed integer nonlinear programming model (1) is developed with the aim of minimizing the total cost of the reverse logistics network for managing product returns. The total cost is comprised of the rent of ICPs, establishment cost of CRCs, inventory carrying cost, product handling cost, and shipping cost. The objective function has a nonlinear form since both inventory carrying cost and shipping cost are affected by a collection period.

$$
\begin{aligned}
& \min \sum_{j} a_{j} Z_{j}+b w \sum_{j} \sum_{i} r_{i} Y_{i j} \frac{T_{j}+1}{2}+h w \sum_{i} r_{i}+\sum_{k} q_{k} G_{k} \\
& \quad+\sum_{k}\left\{G_{k} \sum_{j}\left(X_{j k} \frac{w}{T_{j}+1}\right)\left(E_{j k} \alpha \beta\right)\right\} .
\end{aligned}
$$

Constraint (2) ensures that each customer is assigned to exactly one ICP.

$$
\sum_{j} Y_{i j}=1, \quad \forall i \in I .
$$

Constraint (3) prevents any return flow from a closed ICP.

$$
\sum_{i} Y_{i j} \leq M \cdot Z_{j}, \quad \forall j \in J
$$

Constraint (4) makes the incoming flow equal to the outgoing flow at an ICP.

$$
\sum_{i} r_{i} Y_{i j}\left(T_{j}+1\right)=\sum_{k} X_{j k}, \quad \forall j \in J
$$

Constraint (5) ensures that the total volume of products returned from ICPs does not exceed the maximum capacity of a CRC.

$$
\sum_{j} X_{j k} \leq m_{k} G_{k}, \quad \forall k \in K
$$

Constraint (6) ensures that each ICP should be located within certain allowable proximity to customers.

$$
d_{i j} Y_{i j} \leq 1, \quad \forall i \in I, \forall j \in J .
$$

Constraint (7) ensures a minimum number of established ICPs for product returns.

$$
z \leq \sum_{j} Z_{j}
$$

Constraint (8) ensures a minimum number of established CRCs for product returns.

$$
g \leq \sum_{k} G_{k}
$$

Constraint (9) preserves the nonnegativity of decision variables $X_{j k}$.

$$
X_{j k} \geq 0, \quad \forall j \in J, \forall k \in K .
$$

Constraint (10) ensures the integrality of decision variables $T_{j}$.

$$
T_{j} \in\{0,1,2,3,4,5,6,7\}, \quad \forall j \in J .
$$

Constraint (11) ensures the binary integrality of decision variables $Y_{i j}, Z_{j}$, and $G_{k}$.

$$
Y_{i j}, Z_{j}, G_{k} \in\{0,1\}, \quad \forall i \in I, \forall j \in J, \forall k \in K .
$$

\section{The Modified Plant Growth Simulation Algorithm}

Li et al. [30] put forward the Plant Growth Simulation Algorithm (PGSA). PGSA is a kind of heuristic algorithm based on the theory criterion of plant growth phototropism. PGSA regards the solution space as a plant's growth environment and simulates that the plant's growth points under the influence of light get morphactin in different levels, thus affecting the growth of various parts. At last, the artificial plant in the solution space reaches the optimal solution in the iterating process. Specifically, morphactin is a kind of plant growth hormone. The morphactin concentration of a growth point on the plant is determined by the environmental information and fluctuates with the change of environmental information. The higher the morphactin concentration of a growth point, the greater the probability of the point to grow a new branch. Nowadays, PGSA has been accepted by more and more researchers and has been applied in some areas, such as logistics facility location [31, 32], network optimization [33], reconfiguration of both power distribution network and power transmission network [34, 35], optimization of capacitor placement in a radial distribution network [36], and wireless sensor network localization [37, 38].

PGSA has three advantages [36]: (1) it handles the objective function and the constraints separately, avoiding the trouble of determining the barrier factors; (2) it requires no external parameters, averting the man-made interference; (3) it provides a guiding search direction that continuously changes with the change of the objective function value. These merits make the optimization procedure focus more on the problem itself and not easily be disturbed by external parameters, which are exactly suitable for this problem to find the optimal solution. In the probability model of PGSA, $f(S)$ is a function of judging the environmental quality of a growth point $S$. PGSA provides that the node $S$ shall provide better environment for sprouting a new branch than what the root provides only if $f(S)<f\left(x^{0}\right)$, and thus it 


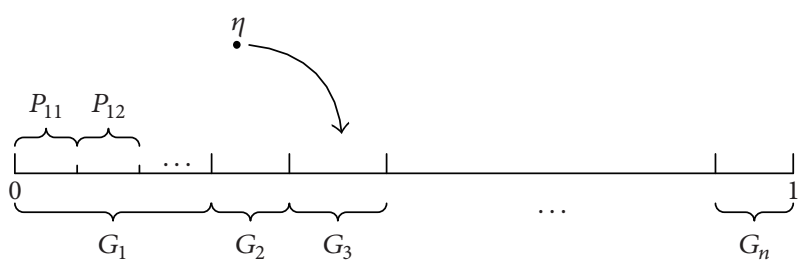

FIgURE 1: Probability model in the original version PGSA.

gets the qualification for a positive growth probability [38]. In one iteration, as shown in Figure 1, on the assumption that there are $m$ growth points from $n$ generations, interval $G_{n}$ represents the state subspace formed by the growth probabilities of growth points from the $N$ th generation; and it also includes a certain number of state subspaces $P_{n i}$, each of which corresponds to the growth probability of growth point $i$ in the $N$ th generation. The sum of growth probabilities of all points equals 1 , formed as a complete state space. Then, a random number $\eta$ obtained in the interval $(0,1)$ is thrown to the state space like a small ball. The subinterval (the growth point) that catches the small ball gets the growth opportunity to sprout a new branch.

This research uses the MPGSA to deal with the network optimization problem depicted in Section 3. The new characteristics in MPGSA will be introduced in the following part. Particularly, this research allocates the products returned by customer $i$ to the nearest ICP $j$, generating the variable $Y_{i j}$; and it allocates the shipment from ICP $j$ to the nearest CRC $k$ when the CRC $k$ is not fulfilled yet, generating the variable $X_{j k}$.

Calculation details are described as follows.

Step $1(k=0)$. Determine the values of both initial basic point (initial solution) $x^{0}$ and step length $\lambda$ and then calculate $f\left(x^{0}\right)$.

$$
\text { Set } X_{\min }=x^{0}, f_{\min }=f\left(x^{0}\right) \text {. }
$$

Step 2 (search for growth points (new feasible solutions)). With point $x^{0}$ as the center, with $\lambda$ as the step length, look for growth points $S_{i_{1} j_{1}}^{0}\left(i_{1}=1,2, \ldots, n ; j_{1}=1,2, \ldots, m_{i_{1}}\right)$ on the axis. $S_{i_{1} j_{1}}^{0}$ indicates the growth point $j_{1}$ on the trunk $i_{1} . m_{i_{1}}$ represents the maximum serial number of growth points on the trunk $i_{1}$.

Step 3 (search for the optimal solution). Compute $f\left(S_{i_{1} j_{1}}^{0}\right)$. And set $f^{*}\left(S_{p_{1} q_{1}}^{0}\right)=\min \left\{f\left(x^{0}\right), f\left(S_{i_{1} j_{1}}^{0}\right)\right\}$.

If $f^{*}\left(S_{p_{1} q_{1}}^{0}\right)<f_{\min }$, then set $X_{\min }=S_{p_{1} q_{1}}^{0}, f_{\min }=$ $f^{*}\left(S_{p_{1} q_{1}}^{0}\right)$.

$$
\text { If } f^{*}\left(S_{p_{1} q_{1}}^{0}\right)=f_{\min } \text {, then set } X_{\min }=\left\{x^{0}, S_{p_{1} q_{1}}^{0}\right\} \text {. }
$$

Step 4. Calculate the growth probability of each growth point, which is also known as concentration of morpheme. 0 .

(1) If $f\left(x^{0}\right) \leq f\left(S_{i_{1} j_{1}}^{0}\right)$, then the growth probability $P_{i_{1} j_{1}}=$
(2) If $f\left(x^{0}\right)>f\left(S_{i_{1} j_{1}}^{0}\right)$, then the growth probability $P_{i_{1} j_{1}}=\left(f\left(x^{0}\right)-f\left(S_{i_{1} j_{1}}^{0}\right)\right) /\left(\sum_{i_{1}=1}^{n} \sum_{j_{1}=1}^{m_{i_{1}}} f\left(x^{0}\right)-f\left(S_{i_{1} j_{1}}^{0}\right)\right)$. And the denominator does not contain the situations where $P_{i_{1} j_{1}}=$ 0 .

Obviously, $\sum_{i_{1}=1}^{n} \sum_{j_{1}=1}^{m_{i_{1}}} P_{i_{1} j_{1}}=1$.

Step 5 (generate a new basic point). Generate a random number $\eta_{0}$ on the interval $(0,1)$. Find the new basic point $S_{l_{1} \mu_{1}}^{0}$ based on the constraint $\sum_{i_{1}=1}^{l_{1}} \sum_{j_{1}=1}^{\mu_{1}-1} P_{i_{1} j_{1}}<\eta_{0} \leq$ $\sum_{i_{1}=1}^{l_{1}} \sum_{j_{1}=1}^{\mu_{1}} P_{i_{1} j_{1}}$.

Step 6 (search for growth points). Set $k=k+1$ and set $x^{k}=$ $S_{l_{k} \mu_{k}}^{(d-1)}, d \in\{1,2, \ldots, k\}$.

With point $x^{k}$ as the center, with $\lambda$ as the step length, look for growth points $S_{i_{k+1} j_{k+1}}^{k}\left(i_{k+1}=1,2, \ldots, n ; j_{k+1}=1\right.$, $\left.2, \ldots, m_{i_{k+1}}\right)$ on the axis. $S_{i_{k+1} j_{k+1}}^{k}$ indicates the growth point $j_{k+1}$ on the branch $i_{k+1} \cdot m_{i_{k+1}}$ represents the maximum serial number of growth points on the branch $i_{k+1}$.

Step 7 (search for the optimal solution). Compute $f\left(x^{k}\right)$ and $f\left(S_{i_{k+1} j_{k+1}}^{k}\right)$. And set $f^{*}\left(S_{p_{k+1} q_{k+1}}^{k}\right)=\min \left\{f\left(x^{k}\right), f\left(S_{i_{k+1} j_{k+1}}^{k}\right)\right\}$.

If $f^{*}\left(S_{p_{k+1} q_{k+1}}^{k}\right)<f_{\min }$, then set $X_{\text {min }}=S_{p_{k+1} q_{k+1}}^{k}, f_{\text {min }}=$ $f^{*}\left(S_{p_{k+1} q_{k+1}}^{k}\right)$.

If $f^{*}\left(S_{p_{k+1} q_{k+1}}^{k}\right)=f_{\min }$, then set $X_{\min }=\left\{S_{p_{k} q_{k}}^{k-1}, S_{p_{k+1} q_{k+1}}^{k}\right\}$.

Step 8. Calculate the growth probability of each growth point, which is also known as concentration of morpheme.

(1) For the growth points on the trunks,

if $f\left(x^{0}\right) \leq f\left(S_{i_{1} j_{1}}^{0}\right)$, then the growth probability $P_{i_{1} j_{1}}=$ 0

$$
\text { if } f\left(x^{0}\right)>f\left(S_{i_{1} j_{1}}^{0}\right) \text {, then the growth probability } P_{i_{1} j_{1}}=
$$$$
\left(f\left(x^{0}\right)-f\left(S_{i_{1} j_{1}}^{0}\right)\right) /\left(\Delta_{1}+\Delta_{2}+\cdots+\Delta_{k+1}\right) .
$$

In addition,

$$
\begin{aligned}
& \Delta_{1}=\sum_{i_{1}=1}^{n} \sum_{j_{1}=1}^{m_{i_{1}}}\left(f\left(x^{0}\right)-f\left(S_{i_{1} j_{1}}^{0}\right)\right), \\
& \Delta_{2}=\sum_{i_{2}=1}^{n} \sum_{j_{2}=1}^{m_{i_{2}}}\left(f\left(x^{0}\right)-f\left(S_{i_{2} j_{2}}^{1}\right)\right),
\end{aligned}
$$

$$
\Delta_{k+1}=\sum_{i_{k+1}=1}^{n} \sum_{j_{k+1}=1}^{m_{i_{k+1}}}\left(f\left(x^{0}\right)-f\left(S_{i_{k+1} j_{k+1}}^{k}\right)\right),
$$

which do not contain the situations where the growth probabilities are equal to zero.

(2) For the growth points on the branches where $K=1$, if $f\left(x^{0}\right) \leq f\left(S_{i_{2} j_{2}}^{1}\right)$, then the growth probability $P_{i_{2} j_{2}}=$ 0 ; 
if $f\left(x^{0}\right)>f\left(S_{i_{2} j_{2}}^{1}\right)$, then the growth probability $P_{i_{2} j_{2}}=$ $\left(f\left(x^{0}\right)-f\left(S_{i_{2} j_{2}}^{1}\right)\right) /\left(\Delta_{1}+\Delta_{2}+\cdots+\Delta_{k+1}\right)$. And the denominator does not contain the situations where the growth probabilities are equal to zero.

$(k+1)$ For the growth points on the branches where $K=k$, if $f\left(x^{0}\right) \leq f\left(S_{i_{K+1} j_{K+1}}^{K}\right)$, then the growth probability $P_{i_{K+1} j_{K+1}}=0$; if $f\left(x^{0}\right)>f\left(S_{i_{K+1}^{K} j_{K+1}}\right)$, then the growth probability $P_{i_{K+1} j_{K+1}}=\left(f\left(x^{0}\right)-f\left(S_{i_{K+1}^{K} j_{K+1}}^{K}\right)\right) /\left(\Delta_{1}+\Delta_{2}+\cdots+\Delta_{k+1}\right)$. And the denominator does not contain the situations where the growth probabilities are equal to zero.

Obviously, $\quad \sum_{i_{1}=1}^{n} \sum_{j_{1}=1}^{m_{i_{1}}} P_{i_{1} j_{1}}+\sum_{i_{2}=1}^{n} \sum_{j_{2}=1}^{m_{i_{2}}} P_{i_{2} j_{2}}+\cdots+$ $\sum_{i_{k+1}=1}^{n} \sum_{j_{k+1}=1}^{m_{i_{k+1}}} P_{i_{k+1} j_{k+1}}=1$.

Step 9 (generate a new basic point). Generate a random number $\eta_{k}$ on the interval $(0,1)$.

(1) If $\sum_{i_{1}=1}^{l_{k+1}} \sum_{j_{1}=1}^{\mu_{k+1}-1} P_{i_{1} j_{1}}<\eta_{k} \leq \sum_{i_{1}=1}^{l_{k+1}} \sum_{j_{1}=1}^{\mu_{k+1}} P_{i_{1} j_{1}}$, then select $S_{l_{k+1} \mu_{k+1}}^{0}$ as the new basic point.

(2) If $\left(\sum_{i_{1}=1}^{n} \sum_{j_{1}=1}^{m_{i_{1}}} P_{i_{1} j_{1}}+\sum_{i_{2}=1}^{l_{k+1}} \sum_{j_{2}=1}^{\mu_{k+1}-1} P_{i_{2} j_{2}}\right)<\eta_{k} \leq$ $\left(\sum_{i_{1}=1}^{n} \sum_{j_{1}=1}^{m_{i_{1}}} P_{i_{1} j_{1}}+\sum_{i_{2}=1}^{l_{k+1}} \sum_{j_{2}=1}^{\mu_{k+1}} P_{i_{2} j_{2}}\right)$, then select $S_{l_{k+1} \mu_{k+1}}^{1}$ as the new basic point.

$(k+1)$ If $\left(\sum_{i_{1}=1}^{n} \sum_{j_{1}=1}^{m_{i_{1}}} P_{i_{1} j_{1}}+\sum_{i_{2}=1}^{n} \sum_{j_{2}=1}^{m_{i_{2}}} P_{i_{2} j_{2}}+\cdots+\right.$ $\left.\sum_{i_{k+1}=1}^{l_{k+1}} \sum_{j_{k+1}=1}^{\mu_{k+1}-1} P_{i_{k+1} j_{k+1}}\right)<\eta_{k} \leq\left(\sum_{i_{1}=1}^{n} \sum_{j_{1}=1}^{m_{i_{1}}} P_{i_{1} j_{1}}+\right.$ $\left.\sum_{i_{2}=1}^{n} \sum_{j_{2}=1}^{m_{i_{2}}} P_{i_{2} j_{2}}+\cdots+\sum_{i_{k+1}=1}^{l_{k+1}} \sum_{j_{k+1}=1}^{\mu_{k+1}} P_{i_{k+1} j_{k+1}}\right)$, then select $S_{l_{k+1} \mu_{k+1}}^{k}$ as the new basic point.

Give the selected one a unified form as $S_{l_{k+1} \mu_{k+1}}^{(d-1)}, d \in$ $\{1,2, \ldots, k+1\}$.

Step 10. When the latest value of $f_{\min }$ repeats $m$ times, stop the iteration. And set the optimal solution $x^{*}=x_{\min }$; meanwhile, the optimal result $f^{*}=f_{\min }$. Otherwise, return to Step 6.

While operating the original version PGSA based on the model built in Section 3, two contradictory drawbacks gradually show up. On the one hand, as the iteration is going on, data volume in a generation increases wildly, mixed with some obviously inferior solutions slowing the calculation speed. On the other hand, it is hard to allege that a hidden descendant will carry an inferior objective function value when its parent performs poorly. Having summed up experiences constantly, this study makes three improvements.

Improvement 1. In both Steps 2 and 6, check the growth points using the constraints in the mathematical model and then delete the growth points beyond the border of the solution space.

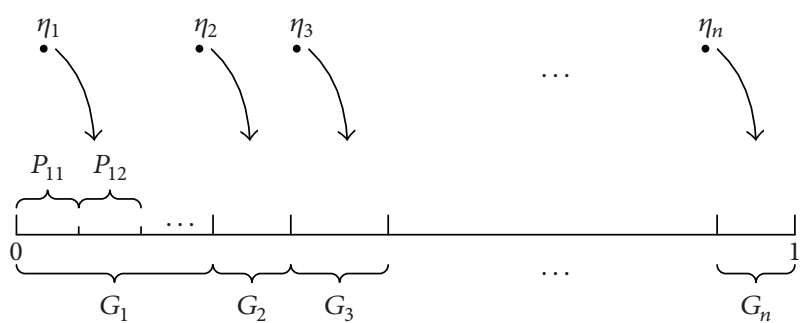

Figure 2: Probability model in MPGSA.

Improvement 2. At the ends of both Steps 3 and 7 , judge the qualities of the growth points using a preset threshold which is set according to the specific problem and the experimental effect. The threshold here is set to 20000 . When the difference between a growth point and the value of $f_{\min }$ is greater than the threshold, the competitiveness of the growth point is weak comparatively. And the growth point is so inferior that it can be deprived of its growth opportunities.

Improvement 3. In Step 9, PGSA of the original version [30] generates just one new basic point out of all growth points. Discriminatively, this research selects a new basic point from the growth points in each generation, to form a group of new basic points. That is, the Nth generation will have at most $(n-1)$ new basic points, on this basis, looking for the growth points of the next generation. As shown in Figure 2, interval $G_{n}$ represents the state subspace formed by the growth probabilities of growth points in the $N$ th generation. And $n$ small balls are thrown separately to $n$ state subspaces to select $n$ new basic points.

Both Improvements 1 and 2 not only concentrate the assignment of precious growth opportunities on the outstanding growth points, to promise the high quality of optimizing result, but also enhance efficiency through saving the computing resources. These are particularly important for the iterative calculation with a large amount of data. Improvement 3 picks a new basic solution from each generation; in other words, the searching scope is expanded, by which the optimizing efficiency will be improved. At the same time, considering that some special growth points with initially poor performances may own shorter paths to get the optimal solution, the third improvement gives the revaluating and reselecting chances to the growth points in all generations, which can avoid falling into local optimum. These three improvements make the MPGSA.

\section{Data Experiment}

5.1. Basic Data. The case study adopts the basic experimental data from the paper of Diabat et al. [21] with the aim of validating the proposed methodology MPGSA. Basic data in the case include the coordinates information of 30 clusters of customers, 10 ICPs, and 5 CRCs. Additionally, each cluster of customers has a daily demand of returning products. Measurement of the distance uses Euclidean distance. The capacity of each CRC is set to 1000 units. Other input 
TABLE 1: Input parameters in the case study.

\begin{tabular}{lcc}
\hline Parameter & Index & Value \\
\hline Annual rental expense of an ICP & $a$ & $\$ 200$ \\
\hline Daily inventory carrying cost per unit at an ICP & $b$ & $\$ 0.1$ \\
\hline Working days per year & $w$ & 250 \\
\hline Daily product handling cost per unit at an ICP & $h$ & $\$ 0.1$ \\
\hline Cost of establishing a CRC & $q_{k}$ & $\$ 3000$ \\
\hline Capacity of a CRC & $m_{k}$ & 1000 units \\
\hline Service radius of an ICP & $l$ & 25 miles \\
\hline Unit standard transportation cost & $E$ & $\$ 1$ \\
\hline & $\alpha_{1}$ & 0.8 \\
Discount rate according to shipping volume & $\alpha_{2}$ & 0.6 \\
& $p_{1}$ & 200 units \\
& $p_{2}$ & 400 units \\
\hline Penalty rate according to shipping distance & $\beta_{1}$ & 1.1 \\
& $\beta_{2}$ & 1.2 \\
\hline Minimum number of established ICPs & $q_{1}$ & 25 miles \\
\hline Minimum number of established CRCs & $q_{2}$ & 60 miles \\
\hline
\end{tabular}

parameters are listed in Table 1. Basic data is set to the same value as the data used in the study of Diabat et al. [21], to scientifically provide a comparison of optimization effect using different heuristic approaches.

Discount rate $\alpha$ of unit freight has three optional values and is defined in the calculating process according to the shipping volume $X_{j k}$. To encourage batch transport to reduce transportation cost, there is no freight discount when a product volume $X_{j k}$ is not larger than 200 units; discount rate $\alpha$ equals 0.8 when $200<X_{j k} \leq 400$; discount rate $\alpha$ equals 0.6 when $X_{j k}>400$. Similarly, penalty rate $\beta$ has three optional values and is defined in accordance with the shipping distance. There is a positive correlation between the unit freight and the shipping distance, which impels an ICP to choose the nearby CRC to return the products.

$$
\begin{gathered}
\alpha= \begin{cases}1, & X_{j k} \leq p_{1} \\
\alpha_{1}, & p_{1}<X_{j k} \leq p_{2} \\
\alpha_{2}, & X_{j k}>p_{2},\end{cases} \\
\beta= \begin{cases}1, & d_{j k} \leq q_{1} \\
\beta_{1}, & q_{1}<d_{j k} \leq q_{2} \\
\beta_{2}, & d_{j k}>q_{2} .\end{cases}
\end{gathered}
$$

5.2. Experimental Result. This research carries out an experiment 30 times separately under the condition that the iteration in one experiment will not stop until a value of $f_{\min }$ repeats 20 times. And the experiment results are shown in Figure 3. After the data inspection using a box-and-whisker plot (Figure 4), there is no outlier in the sample, which promises the quality of the data to be used in the following

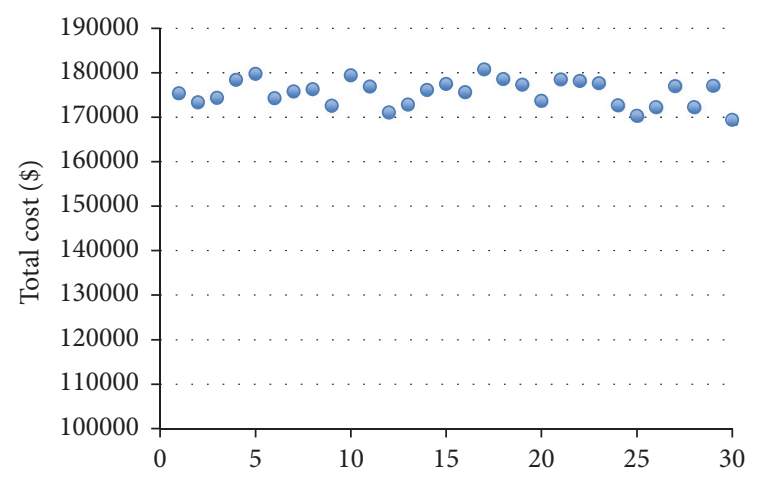

FIGURE 3: Optimization results using MPGSA in 30 experiments.

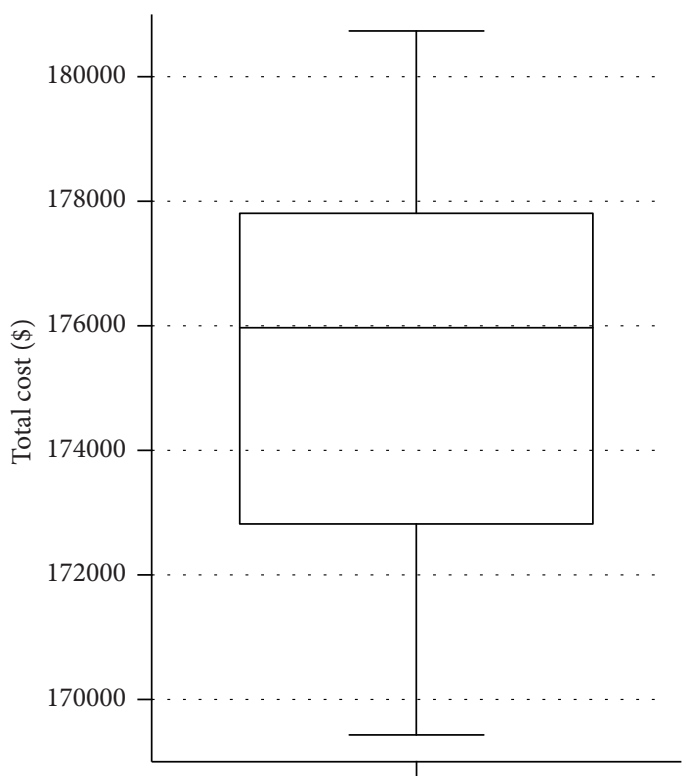

FIGURE 4: Boxplot inspection of the optimization results of MPGSA.

TABLE 2: Calculation results of MPGSA.

\begin{tabular}{lccc}
\hline & Best & Worst & Mean \\
\hline Total cost $(\$)$ & 169435 & 180740 & 175516.80 \\
Iterating times & 88 & 45 & 59.73 \\
\hline
\end{tabular}

analysis. As shown in Table 2, the average of the objective function values is $\$ 175516.80$, and the average number of iterations is 59.73. MPGSA indeed gets a satisfactory effect. Diabat et al. [21] used two approaches, GA and AIS, on the proposed model. Besides, under the premise of both using the same data basis and conducting the same number of experiments (30 times), this study carries out rounds of experiments using PGSA and SA. Comparing five sets of results using five different heuristic algorithms, as illustrated in Figure 5, the mean total cost of the returns network is the lowest using the optimization method MPGSA, reduced by $9.26 \%$ when compared to the result of AIS, reduced by $8.32 \%$ when compared to the result of SA, and reduced by $5.85 \%$ when compared to the result of PGSA. MPGSA achieves a better experiment result significantly. 


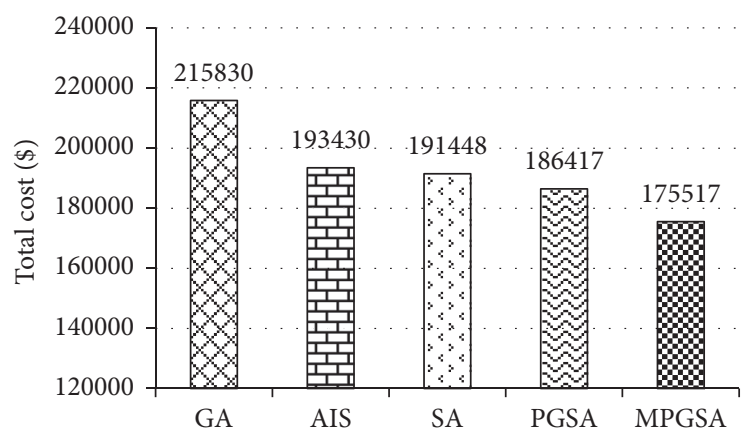

FIGURE 5: Comparison of optimization effects using GA, AIS, SA, PGSA, and MPGSA separately.

TABLE 3: Recommended holding period (in days) of each ICP.

\begin{tabular}{lcccc}
\hline Number & Coordinates & Mean & Minimum & Maximum \\
\hline 1 & $(44,50)$ & 2.6 & 1 & 4 \\
2 & $(2,13)$ & 3 & 2 & 4 \\
3 & $(41,30)$ & 2.7 & 0 & 4 \\
4 & $(5,59)$ & 2.6 & 0 & 4 \\
5 & $(25,19)$ & 2.7 & 1 & 4 \\
6 & $(16,21)$ & 2.4 & 1 & 4 \\
7 & $(30,45)$ & 2.7 & 0 & 4 \\
8 & $(40,0)$ & 2.5 & 0 & 4 \\
9 & $(7,34)$ & 2.8 & 1 & 5 \\
10 & $(55,57)$ & 3 & 2 & 4 \\
\hline
\end{tabular}

According to the simulation result, the CRC with the coordinates of $(32,39)$ is supposed to be closed; and the recommended order of the remaining 4 CRCs to be established, from superior to inferior, is $(20,53),(48,19),(10,7)$, and (9, 30 ). In addition, the average number of CRCs that should be established is 3.17 , which means that it is best to open 3 CRCs in the product returns network.

The optimal solution of each experiment in the round always gives a piece of advice for the holding periods $T_{j}$ of ten ICPs. When the holding period $T_{j}$ of ICP $j$ equals 0, ICP $j$ is not suggested renting. Table 3 shows the mean, the minimum, and the maximum of holding periods (in days) of ten ICPs. For example, the first ICP with the coordinates of $(44,50)$ is advised to keep a holding period of 2.6 days averagely; the shortest can be 1 day; the longest can be 4 days.

5.3. Stability Analysis of MPGSA. Repetitions of $f_{\min }$ can influence the accuracy of the solution directly. To illustrate the stability of MPGSA, this research raises the requirement on repetitions of $f_{\min }$ to 35 times and 50 times, respectively, and runs the algorithm for two rounds. As shown in Table 4, the objective function value indeed decreases as the number of the repetitions of $f_{\min }$ increases, however with a modest extent. In Table 5, the experiment results from three rounds all suggest establishing 3 CRCs; and three ranking results of recommendation extent of 5 alternative CRCs are basically identical. In conclusion, the result generated from MPGSA is stable, which proves the high efficiency of MPGSA. In

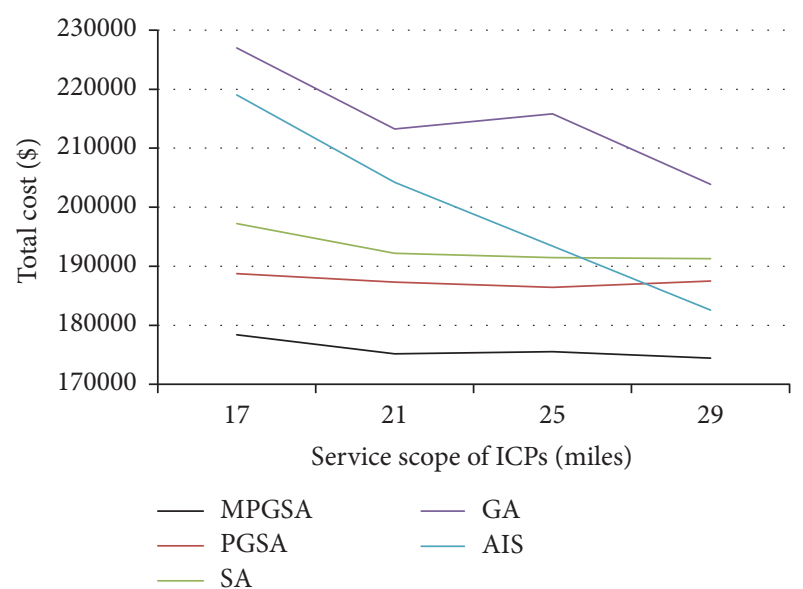

FIGURE 6: Comparison of optimized total costs of five algorithms considering the change of service radius.

addition, Table 6 lists 9 selectable solutions, each of which offers a low-cost advantage, providing the manager with multiple options.

\section{Sensitivity Analysis}

6.1. A Sensitivity Analysis of the Service Scope of ICPs. The locations of ICPs should be close enough to customers to provide convenience for returning products $[39,40]$. Dekker et al. [41] mentioned that the volume of returns is related to the location of collection points, and a reasonable layout of collection points is a primary consideration in the network design. According to Diabat et al. [21], the expansion of the service scope of ICPs will lessen the required number of ICPs, reducing total cost of the product returns network. Therefore, there is an urgent need to find an equilibrium point between reducing logistics cost and improving service level.

This study sets the service radius of each ICP as different sizes (17, 21, 25, and 29 miles) and runs the algorithm MPGSA. The optimization result using MPGSA is compared with the results using PGSA, SA, GA, and AIS, as shown in Table 7 and Figure 6, which is optimal relatively. According to the MPGSA result, the expansion of ICPs' service scopes surely leads to the decrease of total network cost, however with a slight extent. Using nonparametric Friedman test on the result obtained from MPGSA, the small value of $p(=0.0001)$ indicates that the service radius of ICPs affects the total cost at a confidence level of $1 \%$. But it is decreasing not in that way as shown in the experiment of Diabat et al. [21]. The contrast of results displayed in Figure 6 can tell that MPGSA is a more stable and reliable method to find the appropriate locations for ICPs and to arrange the proper collection periods for them. Balancing the total cost with the service quality, the desirable proximity of ICPs should be limited within the range from 21 to 25 miles. Figure 7 summarizes the volatility of MPGSA simulation result under varying proximity. The boxplot shows that the fluctuation range is smaller when the service radius is 25 miles. So the 25 -mile radius is a more appropriate range of ICPs. 
TABLE 4: Calculation results with varying repetitions of $f_{\min }$.

\begin{tabular}{|c|c|c|c|c|c|c|c|c|c|}
\hline & \multicolumn{9}{|c|}{ Repetitions of $f_{\min }$ : total cost in dollars (\$) } \\
\hline & \multicolumn{3}{|c|}{20 times } & \multicolumn{3}{|c|}{35 times } & \multicolumn{3}{|c|}{50 times } \\
\hline & Best & Worst & Mean & Best & Worst & Mean & Best & Worst & Mean \\
\hline MPGSA & 169435 & 180740 & 175517 & 168396 & 176699 & 172580 & 162614 & 174788 & 169657 \\
\hline Iterating times & 88 & 45 & 59.73 & 130 & 110 & 125.30 & 211 & 100 & 190.60 \\
\hline
\end{tabular}

TABLE 5: Consistency analysis on the recommendation of CRCs.

\begin{tabular}{lcccccc}
\hline \multirow{2}{*}{ Repetitions of $f_{\min }$} & \multirow{2}{*}{ AECRC } & \multicolumn{2}{c}{ OSCRC (coordinates) } & \multicolumn{2}{c}{ NECRC (coordinates) } \\
\hline 20 & & Number 1 & Number 2 & Number 3 & Number 4 & $(32,29)$ \\
35 & 3.17 & $(20,53)$ & $(48,19)$ & $(10,7)$ & $(9,30)$ & $(32,29)$ \\
50 & 3.07 & $(20,53)$ & $(10,7)$ & $(48,19)$ & $(9,30)$ & $(32,29)$ \\
\hline
\end{tabular}

(1) AECRC: recommended number of established CRCs on average.

(2) OSCRC: recommended order of selectable CRCs.

(3) NECRC: the CRC should not be established.

TABLE 6: Recommended superior solutions.

\begin{tabular}{lcccccccccccccccccc}
\hline \multirow{2}{*}{ Repetitions of $f_{\text {min }}$} & Number & Total cost & \multicolumn{1}{c}{ Nolding periods of ten ICPs (in days) } & \multicolumn{4}{c}{ Establishment of CRCs } \\
& & $(\$)$ & 1 & 2 & 3 & 4 & 5 & 6 & 7 & 8 & 9 & 10 & 1 & 2 & 3 & 4 & 5 \\
\hline \multirow{3}{*}{20} & 1 & 169435 & 3 & 3 & 0 & 3 & 1 & 2 & 3 & 3 & 2 & 3 & 0 & 0 & 0 & 1 & 1 \\
& 2 & 170330 & 3 & 3 & 3 & 3 & 1 & 4 & 3 & 3 & 1 & 3 & 0 & 0 & 1 & 1 & 1 \\
& 3 & 171120 & 3 & 3 & 3 & 3 & 2 & 2 & 0 & 3 & 3 & 2 & 1 & 0 & 1 & 0 & 1 \\
\hline \multirow{3}{*}{35} & 4 & 168396 & 3 & 3 & 2 & 2 & 1 & 2 & 3 & 1 & 3 & 4 & 1 & 0 & 1 & 0 & 1 \\
& 5 & 168518 & 1 & 2 & 3 & 4 & 3 & 3 & 0 & 3 & 3 & 3 & 1 & 0 & 1 & 1 & 1 \\
& 6 & 168554 & 4 & 3 & 3 & 3 & 1 & 1 & 3 & 1 & 2 & 4 & 1 & 0 & 0 & 1 & 1 \\
\hline \multirow{3}{*}{50} & 7 & 162614 & 2 & 3 & 3 & 3 & 3 & 2 & 0 & 3 & 1 & 3 & 1 & 0 & 1 & 0 & 1 \\
& 8 & 163537 & 1 & 3 & 4 & 2 & 2 & 4 & 3 & 1 & 1 & 1 & 0 & 0 & 0 & 1 & 1 \\
& 9 & 163879 & 2 & 3 & 3 & 3 & 0 & 0 & 2 & 3 & 3 & 2 & 0 & 0 & 1 & 1 & 1 \\
\hline
\end{tabular}

TABLE 7: Sensitivity analysis with varying service radius of ICPs.

\begin{tabular}{|c|c|c|c|c|c|c|c|c|c|c|c|c|}
\hline & \multicolumn{12}{|c|}{ Service radius of ICPs: total cost in dollars (\$) } \\
\hline & \multicolumn{3}{|c|}{17 miles } & \multicolumn{3}{|c|}{21 miles } & \multicolumn{3}{|c|}{25 miles } & \multicolumn{3}{|c|}{29 miles } \\
\hline & Best & Worst & Mean & Best & Worst & Mean & Best & Worst & Mean & Best & Worst & Mean \\
\hline MPGSA & 169093 & 184564 & 178379 & 168146 & 182098 & 175151 & 169435 & 180740 & 175517 & 167592 & 179659 & 174424 \\
\hline PGSA & 182243 & 196197 & 188738 & 182370 & 192929 & 187279 & 178083 & 193473 & 186417 & 180429 & 198208 & 187507 \\
\hline SA & 183110 & 208635 & 197219 & 170636 & 206136 & 192199 & 173146 & 205348 & 191448 & 172553 & 204753 & 191277 \\
\hline GA & 212089 & 236487 & 226980 & 218098 & 225987 & 213234 & 204860 & 225700 & 215830 & 191765 & 213457 & 203876 \\
\hline AIS & 207466 & 223450 & 219020 & 220340 & 222560 & 204237 & 192240 & 195780 & 193430 & 180450 & 185100 & 182560 \\
\hline
\end{tabular}

6.2. A Sensitivity Analysis of Unit Inventory Carrying Cost of ICPs. Daily volume of product returns is so small that an ICP needs to hoard goods in several days to ship them in bulk to CRCs (as shown in Table 3), which will reduce the transportation cost. But, on the other hand, the inventory carrying cost at the ICP will increase. Anyway, it would be a tradeoff between transportation cost and inventory carrying cost. This section tests the wave of total cost with varying unit inventory carrying costs $(0.01,0.05,0.10$, and 0.15 dollars), while keeping the unit freight constant at 1 dollar.
Table 8 lists the MPGSA optimization result, containing the best, the worst, and the mean values of total cost, and compares it with the results obtained from the algorithms of PGSA, SA, GA, and AIS. The comparison given in Figure 8 gives two messages: (1) MPGSA always gets the solution with a lower mean total cost and (2) unit inventory carrying cost has a remarkable influence on the total cost. Based on the Friedman test used on the MPGSA result, $p$ value $=3.88769 e-19$ indicates that the unit inventory carrying cost of ICPs observably influences the network total cost. 
TABLE 8: Sensitivity analysis with varying unit inventory carrying cost.

\begin{tabular}{|c|c|c|c|c|c|c|c|c|c|c|c|c|}
\hline & \multicolumn{12}{|c|}{ Unit inventory carrying cost: total cost in dollars $(\$)$} \\
\hline & \multicolumn{3}{|c|}{$\$ 0.01$} & \multicolumn{3}{|c|}{$\$ 0.05$} & \multicolumn{3}{|c|}{$\$ 0.10$} & \multicolumn{3}{|c|}{$\$ 0.15$} \\
\hline & Best & Worst & Mean & Best & Worst & Mean & Best & Worst & Mean & Best & Worst & Mean \\
\hline MPGSA & 138100 & 144833 & 140758 & 150567 & 160208 & 155278 & 169435 & 180740 & 175517 & 175980 & 200904 & 189573 \\
\hline PGSA & 144711 & 152723 & 148675 & 155046 & 174279 & 164778 & 178083 & 193473 & 186417 & 197029 & 213163 & 207568 \\
\hline SA & 141250 & 165793 & 155607 & 150924 & 184553 & 170577 & 173146 & 205348 & 191448 & 182127 & 227445 & 207318 \\
\hline GA & 173230 & 175090 & 174340 & 189080 & 248070 & 213450 & 204860 & 225700 & 215830 & 211870 & 243450 & 223849 \\
\hline AIS & 172098 & 174090 & 172920 & 182908 & 236590 & 203450 & 192240 & 195780 & 193430 & 209654 & 234560 & 216360 \\
\hline
\end{tabular}

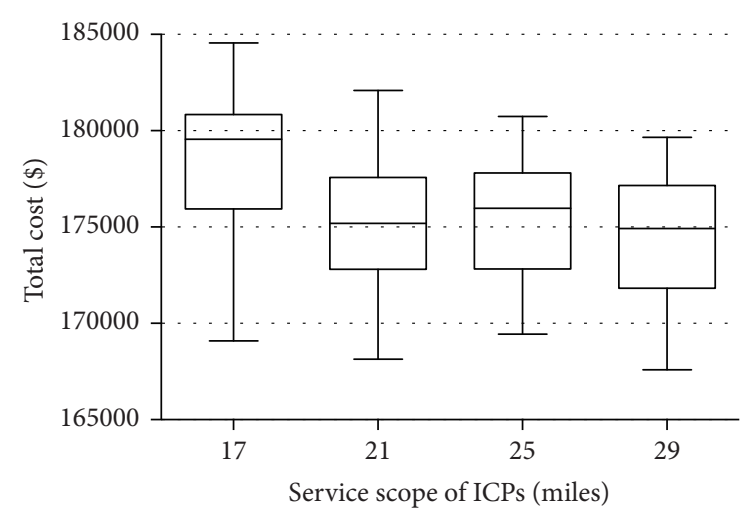

FIGURE 7: Boxplot of total cost with varying service radius using MPGSA.

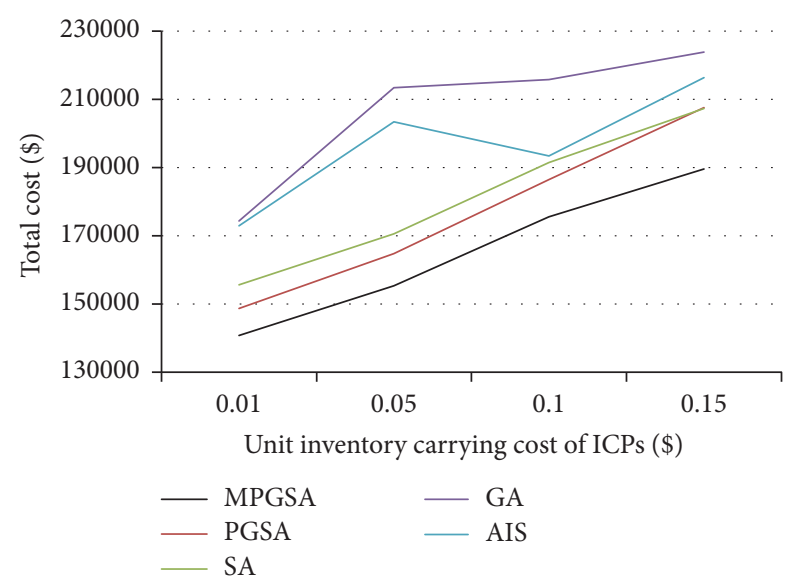

Figure 8: Comparison of optimized total costs of five algorithms considering the change of unit inventory carrying cost.

As shown in Figure 9, the 4 boxes are in different heights, and the separation between each pair of them is obvious. The managerial implication obtained from the experimental results which are displayed in Figure 9 explains that taking an appropriate inventory management strategy at an ICP to lessen unit inventory carrying cost would reduce total cost of the returns network obviously. The inventory carrying cost in reverse logistics includes the out-of-pocket cost and the opportunity cost. And the out-of-pocket cost is related to a series of management activities, such as cargo storage, cargo handling, and cargo repair [42]. That brings about a

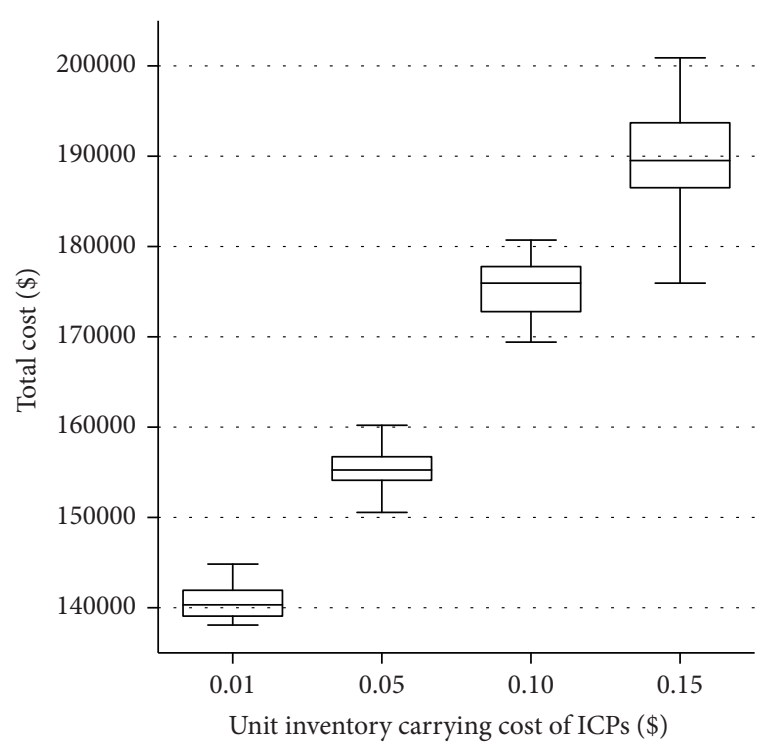

FIGURE 9: Boxplot of total cost with varying unit inventory carrying cost using MPGSA.

management inspiration: an enterprise should make a scientific assessment on the environment for returning product and formulate an accurate inventory control strategy and use advanced handling facilities to improve its work efficiency. Although the upfront investment may be relatively large, the long-term benefits won from reducing the inventory carrying cost of a huge number of goods will be very substantial.

6.3. A Sensitivity Analysis of the Inventory Capacity of CRCs. The construction cost of a CRC is related to the construction scale (i.e., inventory capacity). Assume that the construction cost of a CRC is proportional to the inventory capacity of it. Then, it would take 2700 dollars to build a CRC with a capacity of 900 units, and it would take 3000 dollars to build a CRC with a capacity of 1000 units, and so on. A sensitivity analysis is performed based on the assumption. Table 9 lists the best, the worst, and the mean values of total cost obtained from the data experiment using MPGSA, PGSA, and SA and the average number of MPGSA-recommended CRCs. Figure 10 compares the fluctuation of the mean total costs using the three algorithms along with the expansion of inventory capacity. Figure 11 shows the fluctuation of MPGSA total cost in the form of boxplot. Observably, MPGSA gets 
TABLE 9: Sensitivity analysis with varying capacity of CRCs.

\begin{tabular}{|c|c|c|c|c|c|c|c|c|c|}
\hline & \multicolumn{9}{|c|}{ Capacity of CRCs: total cost in dollars (\$) } \\
\hline & \multicolumn{3}{|c|}{700 units } & \multicolumn{3}{|c|}{800 units } & \multicolumn{3}{|c|}{900 units } \\
\hline & Best & Worst & Mean & Best & Worst & Mean & Best & Worst & Mean \\
\hline MPGSA & 166493 & 178013 & 172685 & 167500 & 176613 & 171961 & 168875 & 177794 & 174149 \\
\hline PGSA & 179429 & 186013 & 182553 & 179058 & 187539 & 183342 & 177933 & 187551 & 183334 \\
\hline SA & 168412 & 203453 & 190507 & 174645 & 202796 & 191490 & 174050 & 203744 & 192501 \\
\hline \multirow[t]{4}{*}{ Number of CRCs using MPGSA } & & 3.83 & & & 3.30 & & & 3.10 & \\
\hline & \multicolumn{9}{|c|}{ Capacity of CRCs: total cost in dollars (\$) } \\
\hline & \multicolumn{3}{|c|}{1000 units } & \multicolumn{3}{|c|}{1100 units } & \multicolumn{3}{|c|}{1200 units } \\
\hline & Best & Worst & Mean & Best & Worst & Mean & Best & Worst & Mean \\
\hline MPGSA & 169435 & 180740 & 175517 & 170308 & 178899 & 175006 & 167766 & 180649 & 174468 \\
\hline PGSA & 178083 & 193473 & 186417 & 183254 & 190123 & 186774 & 180489 & 190030 & 187061 \\
\hline SA & 173146 & 205348 & 191448 & 168646 & 206226 & 192809 & 167500 & 207151 & 191591 \\
\hline Number of CRCs using MPGSA & & 3.17 & & & 2.97 & & & 2.60 & \\
\hline
\end{tabular}

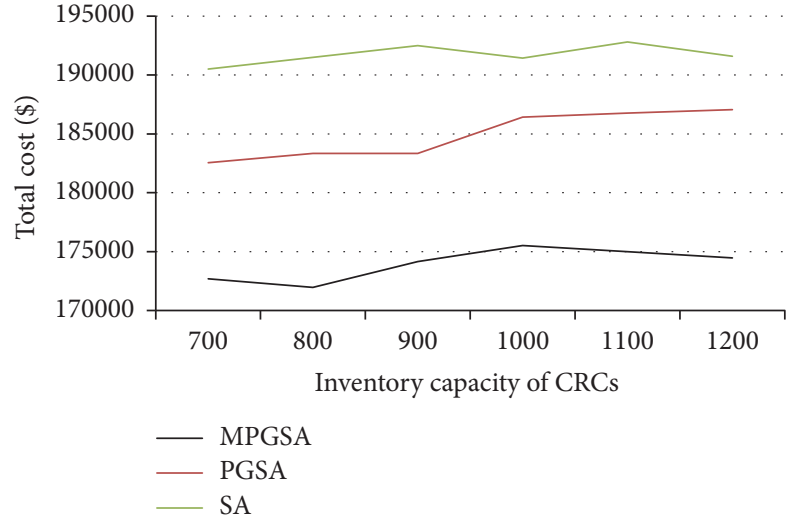

FIGURE 10: Comparison of optimized total costs of three algorithms considering the change of inventory capacity.

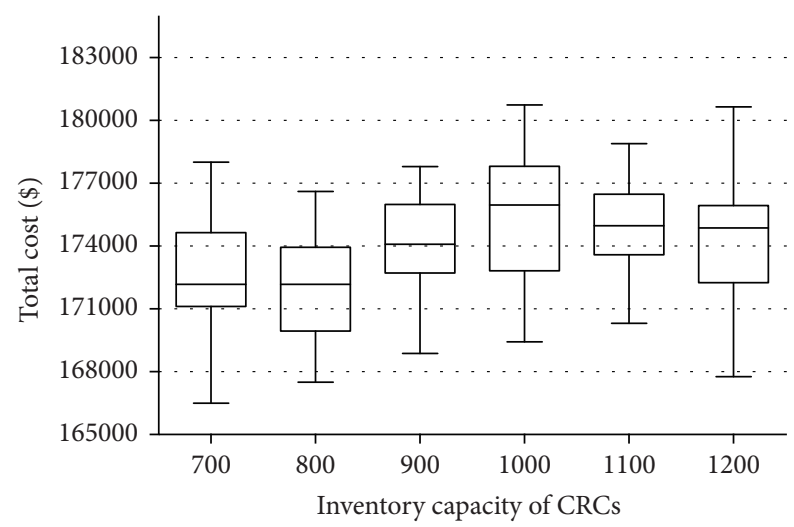

FIGURE 11: Boxplot of total cost with varying inventory capacity using MPGSA.

the optimal solution relatively. As the data illustrates, the larger the inventory capacity, the smaller the number of CRCs needed. Based on the Friedman test used on the MPGSA result, $p$ value $=2.62671 e-05$ reflects that the difference in inventory capacity of CRCs will induce the fluctuation in total cost at a confidence level of $1 \%$. However, expanding the inventory capacity of CRCs is not absolute to bring about an increase or a decrease of total cost. There is an explanation for the MPGSA phenomenon in Figure 11.

(1) When the inventory capacity of a CRC changes from 800 to 1100 units, the recommended number of CRCs stays at around 3. The increase in construction cost resulting from the expansion of inventory capacity raises the total cost slightly. In particular, total cost has a little descent when the inventory capacity changes from 1000 units to 1100 units. Though the expansion of capacity increases the building cost, it allows more ICPs to pick the nearest CRC to return the goods or allows the ICPs to return more goods to the CRC that is near to them, saving the transportation cost. And the decline in transportation cost has a bigger influence on the total cost.

(2) When the inventory capacity keeps in 700 units, MPGSA recommends 3.83 CRCs averagely to be set up. $83.3 \%$ of 30 experiment records suggest establishing 4 CRCs, bringing about the addition of construction cost; at the same time, the sum of inventory capacities of all CRCs is very close to the total volume of returns in one period, which means that most ICPs need to distribute their returns to multiple CRCs, resulting in the increase of transportation cost. As shown in Figure 11, the position of the 700-inventory-capacity box is higher than the position of the 800-inventory-capacity box, which is consistent with the analysis.

(3) When the inventory capacity keeps in 1200 units, MPGSA suggests setting up 2.6 CRCs averagely. In 30 experiment records, $53.3 \%$ of them suggest establishing 3 CRCs, and $43.3 \%$ of them suggest establishing 2, decreasing the building cost averagely; but, on the other hand, when a solution proposes to build $2 \mathrm{CRCs}$, the haul distance will be lengthened for a part of ICPs, increasing the transport cost. As what has been seen in Table 9, the mean total cost is close to the other one when the capacity is set to 1100 units, which means that the decreasing cost offsets the increasing cost when the capacity is enlarged. But the whiskers (in Figure 11) are longer as the capacity equals 1200 units, and thus it is not stable comparatively. 
Considering synthetically the total cost and its stability, this research recommends that the capacity of a CRC should be limited within a region from 800 to 900 units.

\section{Conclusion}

This paper presents a high-efficiency and stable method, the Modified Plant Growth Simulation Algorithm, to solve the location-allocation problem of a product returns network. On the basis of the original version PGSA, this paper makes MPGSA with three improvements to expand the search scope and remove the inferior growth points. The improvements bring about the following good consequences: (1) it concentrates the assignment of precious growth opportunities on the fine growth points to promise a high-quality result; (2) it economizes the computing resources, which is especially meaningful for the iterative calculation with a mountain of data; (3) it picks a new basic solution from each generation to expand the search scope and enhance the optimizing efficiency, though the data volume calculated increases rapidly along with the propelling of iteration; (4) considering that some initially weak growth points may own shorter paths to get the optimal solution, it gives the revaluating and reselecting chances to all growth points in each iteration, to avoid falling into a local optimum.

The mathematical model proposed here focuses on the management of returning products only. Compared to other models proposed in reverse logistics and closed-loop supply chain that cover so many sections in supply chain, which are too rough to provide clearly and easily understandable solutions, the model presented here is more detailed and complete on the depiction of the network structure, operation costs, and duration control, giving practicable and easycontrolled solutions to managers and decision-makers. The three-echelon product returns network accords with the universal requirement in the real world. And it has good adaptability in being developed to support other multiechelon networks to cover a vaster area.

The numerical result indicates that MPGSA is effective and stable. The average total cost of the product returns network using MPGSA reaches the lowest level, reduced by $9.26 \%$ when compared to the result of AIS, reduced by $8.32 \%$ when compared to the result of SA, and reduced by $5.85 \%$ when compared to the result of PGSA. These improvements of MPGSA can be applied in more optimization researches in the future as they have just one objective function.

This research uses static data in the calculation process in order to make scientific comparison of the optimization effects of various algorithms. Future work can perform network optimization considering the uncertainty of returnproduct needs. Furthermore, it is worthwhile to design a sustainable network for product returns, which aims equally at sustainability in economic, environmental, and social dimensions.

\section{Competing Interests}

The authors declare that there are no competing interests regarding the publication of this paper.

\section{Acknowledgments}

The authors are grateful to the financial support by the National Natural Science Foundation of China (nos. 71471025, 71531002, and 71671022) and China Ministry of Education Social Sciences and Humanities Research Youth Fund Project (no. 16YJC630102).

\section{References}

[1] S. Rao, E. Rabinovich, and D. Raju, "The role of physical distribution services as determinants of product returns in Internet retailing," Journal of Operations Management, vol. 32, no. 6, pp. 295-312, 2014.

[2] E. Rabinovich, R. Sinha, and T. Laseter, "Unlimited shelf space in Internet supply chains: treasure trove or wasteland?" Journal of Operations Management, vol. 29, no. 4, pp. 305-317, 2011.

[3] S. L. Wood, "Remote purchase environments: the influence of return policy leniency on two-stage decision processes," Journal of Marketing Research, vol. 38, no. 2, pp. 157-169, 2001.

[4] D. S. Rogers, D. M. Lambert, K. L. Croxton, and S. J. García-Dastugue, "The returns management process," The International Journal of Logistics Management, vol. 13, no. 2, pp. $1-18,2002$.

[5] S. E. Griffis, S. Rao, T. J. Goldsby, and T. T. Niranjan, “The customer consequences of returns in online retailing: an empirical analysis," Journal of Operations Management, vol. 30, no. 4, pp. 282-294, 2012.

[6] F. Jaehn, "Sustainable operations," European Journal of Operational Research, vol. 253, no. 2, pp. 243-264, 2016.

[7] K. Govindan, H. Soleimani, and D. Kannan, "Reverse logistics and closed-loop supply chain: a comprehensive review to explore the future," European Journal of Operational Research, vol. 240, no. 3, pp. 603-626, 2015.

[8] V. D. R. Guide Jr. and L. N. van Wassenhove, "The evolution of closed-loop supply chain research," Operations Research, vol. 57, no. 1, pp. 10-18, 2009.

[9] P. Georgiadis and M. Besiou, "Environmental and economical sustainability of WEEE closed-loop supply chains with recycling: a system dynamics analysis," International Journal of Advanced Manufacturing Technology, vol. 47, no. 5-8, pp. 475493, 2010.

[10] O. Kaya, F. Bagci, and M. Turkay, "Planning of capacity, production and inventory decisions in a generic reverse supply chain under uncertain demand and returns," International Journal of Production Research, vol. 52, no. 1, pp. 270-282, 2014.

[11] M. Jeihoonian, M. K. Zanjani, and M. Gendreau, "Accelerating Benders decomposition for closed-loop supply chain network design: case of used durable products with different quality levels," European Journal of Operational Research, vol. 251, no. 3, pp. 830-845, 2016.

[12] H. Min, C. S. Ko, and H. J. Ko, "The spatial and temporal consolidation of returned products in a closed-loop supply chain network," Computers and Industrial Engineering, vol. 51, no. 2, pp. 309-320, 2006.

[13] M. Eskandarpour, E. Masehian, R. Soltani, and A. Khosrojerdi, "A reverse logistics network for recovery systems and a robust metaheuristic solution approach," International Journal of Advanced Manufacturing Technology, vol. 74, no. 9-12, pp. 1393-1406, 2014. 
[14] M. Fleischmann, P. Beullens, J. M. Bloemhof-Ruwaard, and L. N. Van Wassenhove, "The impact of product recovery on logistics network design," Production and Operations Management, vol. 10, no. 2, pp. 156-173, 2001.

[15] A. Chaabane, A. Ramudhin, and M. Paquet, "Design of sustainable supply chains under the emission trading scheme," International Journal of Production Economics, vol. 135, no. 1, pp. 37-49, 2012.

[16] V. D. R. Guide Jr., G. C. Souza, L. N. van Wassenhove, and J. D. Blackburn, "Time value of commercial product returns," Management Science, vol. 52, no. 8, pp. 1200-1214, 2006.

[17] T. R. P. Ramos, M. I. Gomes, and A. P. Barbosa-Póvoa, "Planning a sustainable reverse logistics system: balancing costs with environmental and social concerns," Omega, vol. 48, pp. 60-74, 2014.

[18] A. Goel, C. Archetti, and M. Savelsbergh, “Truck driver scheduling in Australia," Computers \& Operations Research, vol. 39, no. 5, pp. 1122-1132, 2012.

[19] K. Devika, A. Jafarian, and V. Nourbakhsh, "Designing a sustainable closed-loop supply chain network based on triple bottom line approach: a comparison of metaheuristics hybridization techniques," European Journal of Operational Research, vol. 235, no. 3, pp. 594-615, 2014.

[20] H. Min, H. J. Ko, and C. S. Ko, "A genetic algorithm approach to developing the multi-echelon reverse logistics network for product returns," Omega, vol. 34, no. 1, pp. 56-69, 2006.

[21] A. Diabat, D. Kannan, M. Kaliyan, and D. Svetinovic, "An optimization model for product returns using genetic algorithms and artificial immune system," Resources, Conservation and Recycling, vol. 74, pp. 156-169, 2013.

[22] N. Zaarour, E. Melachrinoudis, M. Solomon, and H. Min, "A reverse logistics network model for handling returned products," International Journal of Engineering Business Management, vol. 6, no. 1, article 13, pp. 1-10, 2014.

[23] V. Ghezavati and N. S. Nia, "Development of an optimization model for product returns using genetic algorithms and simulated annealing," Soft Computing, vol. 19, no. 11, pp. 3055-3069, 2015.

[24] R. Ruiz-Benítez, M. Ketzenberg, and E. A. van der Laan, "Managing consumer returns in high clockspeed industries," Omega, vol. 43, pp. 54-63, 2014.

[25] J. Ruan and Y. Shi, "Monitoring and assessing fruit freshness in IOT-based e-commerce delivery using scenario analysis and interval number approaches," Information Sciences, vol. 373, pp. 557-570, 2015.

[26] H. Gierl, M. Plantsch, and J. Schweidler, "Scarcity effects on sales volume in retail," The International Review of Retail, Distribution \& Consumer Research, vol. 18, no. 1, pp. 45-61, 2008.

[27] K. J. Crocker and P. Letizia, "Optimal policies for recovering the value of consumer returns," Production and Operations Management, vol. 23, no. 10, pp. 1667-1680, 2014.

[28] G. Ji, A. Gunasekaran, and G. Yang, "Constructing sustainable supply chain under double environmental medium regulations," International Journal of Production Economics, vol. 147, pp. 211-219, 2014.

[29] H. Soleimani and K. Govindan, "Reverse logistics network design and planning utilizing conditional value at risk," European Journal of Operational Research, vol. 237, no. 2, pp. 487-497, 2014.
[30] T. Li, C.-F. Wang, W.-B. Wang, and W.-L. Su, "Global optimization bionics algorithm for solving integer programmingplant growth simulation algorithm," System Engineering Theory \& Practice, vol. 25, no. 1, pp. 76-85, 2005.

[31] T. Li and Z.-T. Wang, "Application of plant growth simulation algorithm on solving facility location problem," Systems Engineering-Theory \& Practice, vol. 28, no. 12, pp. 107-115, 2008.

[32] X. Ding, L. Ma, and X. Ding, “The location allocation of logistics center of perishable products based on plant growth simulation algorithm," Systems Engineering, vol. 27, no. 2, pp. 96-101, 2009.

[33] T. Li and Z.-T. Wang, "Optimization layout of underground logistics network in big cities with plant growth simulation algorithm," Systems Engineering-Theory \& Practice, vol. 33, no. 4, pp. 971-980, 2013.

[34] C. Wang and H.-Z. Cheng, "Reconfiguration of distribution network based on plant growth simulation algorithm," Proceedings of the Chinese Society of Electrical Engineering, vol. 27, no. 19, pp. 50-55, 2007.

[35] C. Wang and H. Cheng, "A plant growth simulation algorithm and its application in power transmission network planning," Automation of Electric Power Systems, vol. 31, no. 7, pp. 24-28, 2007.

[36] R. S. Rao, S. V. L. Narasimham, and M. Ramalingaraju, “Optimal capacitor placement in a radial distribution system using plant growth simulation algorithm," International Journal of Electrical Power and Energy Systems, vol. 33, no. 5, pp. 1133-1139, 2011.

[37] C. Tang, R. Liu, and J. Ni, “A novel wireless sensor network localization approach: localization based on plant growth simulation algorithm," Electronics \& Electrical Engineering, vol. 19, no. 8, pp. 97-100, 2013.

[38] S. Lu and S. Yu, "A fuzzy $k$-coverage approach for RFID network planning using plant growth simulation algorithm," Journal of Network and Computer Applications, vol. 39, pp. 280-291, 2014.

[39] J. H. Ruan, X. P. Wang, F. T. S. Chan, and Y. Shi, "Optimizing the intermodal transportation of emergency medical supplies using balanced fuzzy clustering," International Journal of Production Research, vol. 54, no. 14, pp. 4368-4386, 2016.

[40] C. K. M. Lee and T. M. Chan, "Development of RFID-based reverse logistics system," Expert Systems with Applications, vol. 36, no. 5, pp. 9299-9307, 2009.

[41] R. Dekker, M. Fleischmann, K. Inderfurth, and L. N. Van Wassenhove, Reverse Logistics, Springer Berlin Heidelberg, Berlin, Germany, 2004.

[42] E. Akçali and Z. P. Bayindir, "Analyzing the effects of inventory cost setting rules in a disassembly and recovery environment," International Journal of Production Research, vol. 46, no. 1, pp. 267-288, 2008. 

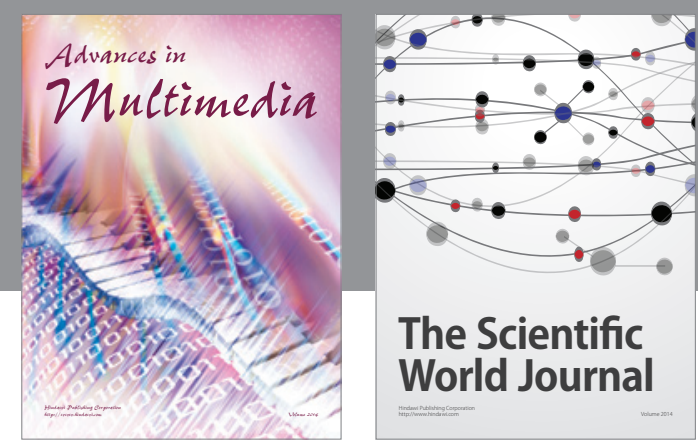

The Scientific World Journal
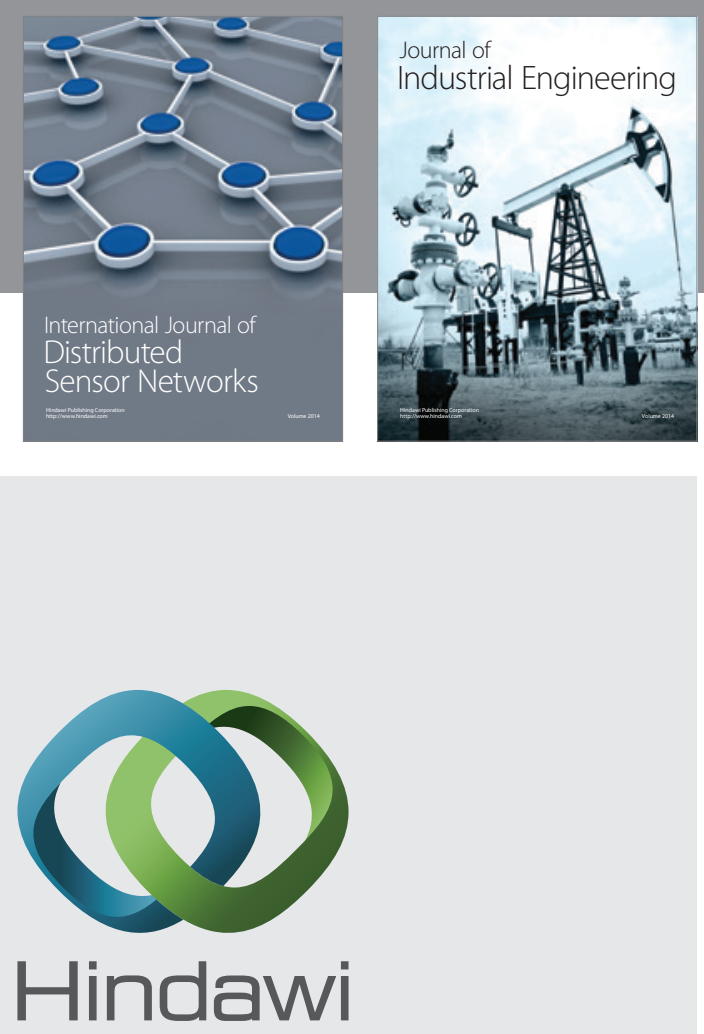

Submit your manuscripts at

https://www.hindawi.com

\section{Computer Networks} and Communications
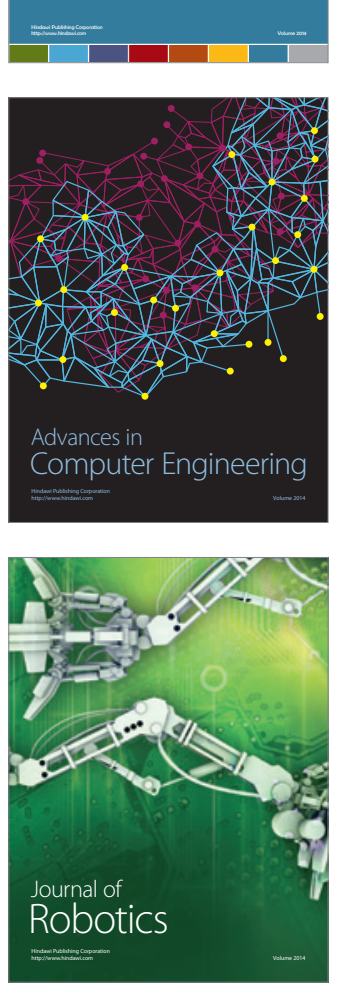
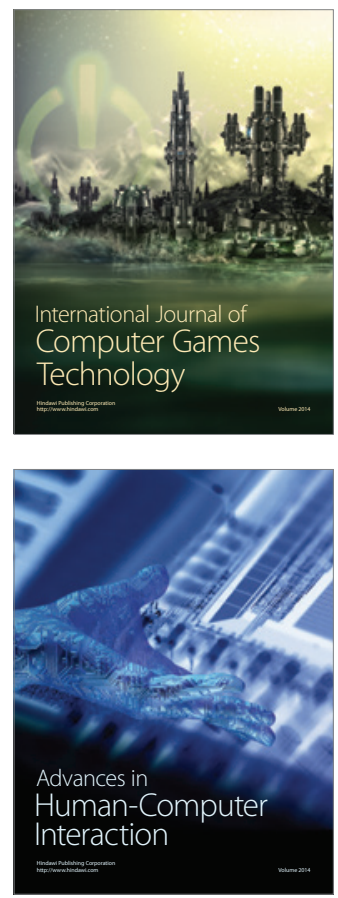
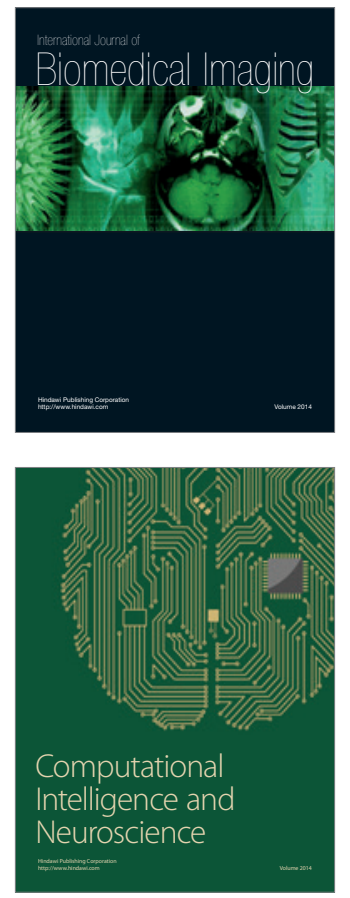
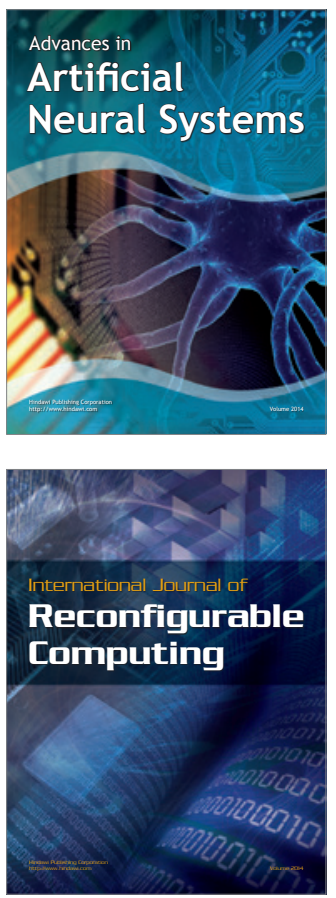
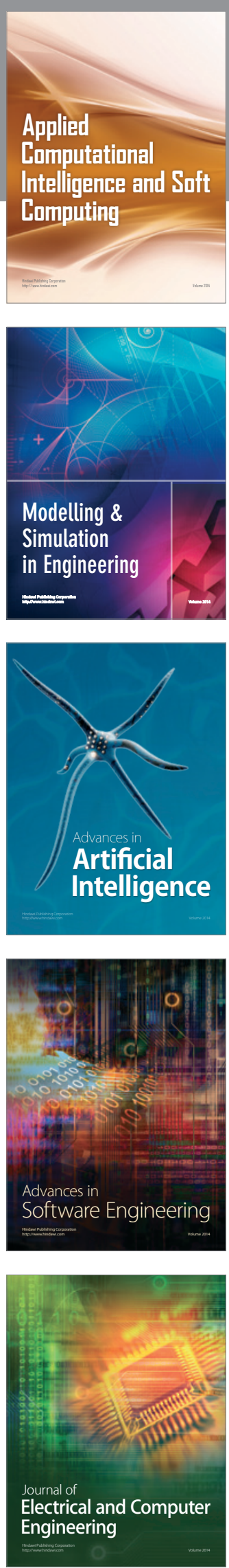